\title{
A Proposal for a Flexible Service Plan that is Attractive to Users and Internet Service Providers
}

\author{
Jörn Altmann \\ e-mail: altmann@eecs.berkeley.edu \\ Electrical Engineering and Computer Science \\ University of California at Berkeley and \\ Internet and Mobil Systems Lab \\ Hewlett-Packard Laboratories \\ 19420 Homestead Road, MS 43UF \\ Cupertino, CA 95014, USA \\ Karyen Chu \\ e-mail: kchu@econ.berkeley.edu \\ Department of Economics \\ University of California at Berkeley \\ 549 Evans Hall \\ Berkeley, CA 94720-3880, USA
}

\begin{abstract}
The current Internet Service Provider market does not offer different types of service plans for Internet access. The predominant pricing plan is a flat-rated plan. Since the number of new Internet users is still growing very fast, there is no real competition in the Internet market. Consequently, there is no incentive for Internet Service Providers (ISPs) to focus on certain user groups by offering more attractive pricing plans in order to differentiate themselves. However, as soon as the number of new Internet users stagnats, ISPs have to specialize on certain market segments. Then, the question raises what is an attractive service plan that is attractive for users, but allows ISPs to build a sustainable business.

Based on empirical results of the INDEX project, we discuss a service plan for Internet access that might be appreciated by Internet users as well as by ISPs. This service plan combines the advantages of flat-rate pricing and usage-based pricing. Using this service plan, users will benefit by receiving a basic service, but are given the choice of higher quality whenever they demand. From the ISP perspective, it will help to focus on certain user groups and limit the peak load on their network.

Keywords - Internet service plans, user demand for Internet access, quality of service, experimental studies.
\end{abstract}

\section{INTRODUCTION}

The primary service plan currently offered by both dial-up and broadband Internet Service Providers (ISPs) in the USA is a flat-rate service plan. This plan offers unlimited access for a flat monthly charge, which is typically approximately $\$ 22$ per month for dial-up Internet service and approximately $\$ 10$ to $\$ 200$ per month for broadband Internet service. Common to these flat-rate unlimited-access service plans, users are only provided with access to a single maximum bandwidth, without the ability to select a higher bandwidth on demand. Users who want access to higher bandwidths must pay a higher monthly fee for unlimited access to that higher bandwidth. For example, Pacific Bell currently offers unlimited DSL access at speed

This research was supported by grants from the National Science Foundation, Cisco Systems, SBC Communications, the California State MICRO Program, and the European Union's Fifth Framework Project M3I (MarketManaged Multiservice Internet - RTD No IST-1999-11429) of $384 \mathrm{kbps}$ downstream and $128 \mathrm{kbps}$ upstream for $\$ 49.95$ per month (\$39.95 for DSL line and \$10 for IP backbone service). Users who want access to a higher bandwidth must pay $\$ 199$ per month which gives them unlimited access to $1.5 \mathrm{Mbps}$ downstream and $384 \mathrm{kbps}$ upstream.

Flat-rate unlimited-access service plans are economically inefficient: Users do not face the true marginal cost of usage, resulting in over-usage and potentially higher than socially optimal levels of infrastructure investment to meet the demand. The high levels of usage under flat-rate unlimited-access service plans have the potential to reduce the overall performance under broadband access technologies. In addition, light users subsidize heavy users. Despite these inefficiencies, these plans predominate.

For the analysis presented in this paper, we use data gathered within the INDEX project (INternet Demand EXperiment) to provide an estimate of the magnitude of increase in usage under flat-rate unlimited-access service plans compared with usage-based pricing plans. Users prefer flat-rate pricing to usage-based pricing when the flat-rate charge is comparable to current unlimited access subscription prices charged by most major commercial ISPs. However, we also show that INDEX subjects take advantage of on-demand access to higher bandwidths when such access is available.

These findings suggest that ISPs may want to consider introducing a new type of service plan: one that provides flatrate unlimited access to basic service with the ability to access higher quality service on demand for which users are charged for their usage. Such a service plan accords with users' preferences and limits the potential reduction in performance of the network due to congestion from over-usage.

The paper proceeds as follows: In the next section, we describe the INDEX experiments and subjects. In section 3, 
we estimate the magnitude of increase in usage under flat-rate unlimited-access service plans compared with usage-based service plans. We show that the ISP also receives significantly lower per MB revenues under flat-rate unlimited-access service plans. In section 4 , we present evidence that INDEX subjects, despite their heterogeneity, prefer flat-rate pricing to usage-based pricing when the flat-rate charge is comparable to current unlimited use subscription prices charged by most major commercial ISPs. In section 5, we explain that the INDEX subjects are willing to pay usage-based charges to access higher bandwidths on demand even after they have paid for unlimited access to a lower bandwidth. We conclude in section 6 with a short discussion of our proposed new pricing plan.

\section{INDEX}

INDEX, the INternet Demand EXperiment, is a market experiment to measure demand for Internet access as a function of quality of service (QoS), service plan, and application. INDEX subjects are provided Internet access over ISDN lines and pay for their usage of the network service. They choose their desired network service from a menu of QoS-price offerings, which currently consists of different bandwidth-price choices.

The menu of quality of service choices and the service plans change every six to ten weeks, moving the subjects through a sequence of experiments that are designed to measure user response to various quality differentiated, usage-based service plans. The approximately 70 subjects currently in the experiment include faculty, staff, and students of the University of California at Berkeley.

\section{A. Minute Pricing Experiments}

During Minute Pricing experiments, INDEX subjects are charged per minute rates for connecting to the Internet at each of five different bandwidths above 8 kbps. ${ }^{1}$ The five bandwidths are: 16kbps, $32 \mathrm{kbps}, 64 \mathrm{kbps}, 96 \mathrm{kbps}$, and $128 \mathrm{kbps}$. Subjects can select any of the offered bandwidths at any time and it was even possible to change bandwidths during an active session. There are two kind of Minute Pricing Experiments: Symmetric Bandwidth and Asymmetric Bandwidth. In the Symmetric Bandwidth Experiment, the selected bandwidth is the same for upstream (out-bound) and downstream (in-bound) traffic. In the Asymmetric Bandwidth Experiment, subjects can select different bandwidths for upstream and downstream traffic.

Both experiments run for seven weeks, which includes a free first week to allow subjects to experience the different bandwidths so that they would be able to make informed choices in the subsequent weeks. In the Symmetric Bandwidth experiment, prices change weekly in weeks two through six, and daily in week seven. In the Asymmetric Bandwidth experiment, prices change weekly in weeks two through seven.

\footnotetext{
${ }^{1} 8 \mathrm{kbps}$ service is always available and priced at zero cent per minute in every experiment to give INDEX subjects an alternative within the experiment to the campus modem pool which is also free of usage charges.
}

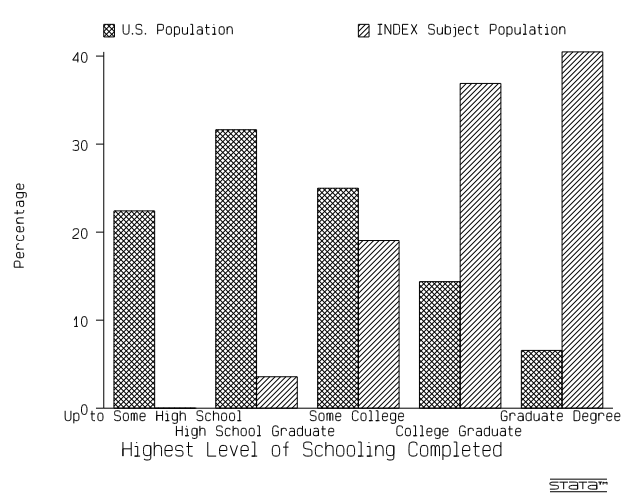

Fig. 1. Educational Achievements of INDEX Subjects and of the U.S. Population

\section{B. Byte Pricing Experiment}

In the Byte Pricing experiment, INDEX subjects are given the choice of two bandwidths: $8 \mathrm{kbps}$, which is free of usage charges, and $128 \mathrm{kbps}$, whose usage is charged according to the number of bytes transmitted. The experiment runs for a total of seven weeks. Week one is again unpriced to allow subjects to learn about the volume of traffic that they generate. In weeks two through seven, the per-byte prices changed every week.

\section{Flat-Rate Buy-Out Option Experiment}

In the Flat-Rate Buy-Out Option experiment, the INDEX subjects are charged per-minute rates for the five priced bandwidths. ${ }^{2}$ The subjects are given the opportunity to buy out any of the five bandwidths for one week by paying a fixed charge. Buying out a bandwidth gives a subject unlimited access at the bought-out bandwidth for the week without having to pay the per-minute prices. The fixed price for buying out all five bandwidths was randomly drawn. The fixed charge for buying out any of the lower four bandwidths was a fraction of the weekly buy-out price. ${ }^{3}$ The subjects' buy-out decisions are binding for the rest of the week and can not be changed until the following week when the following week's buy-out price is revealed to them. After subjects bought out a particular bandwidth, they can continue to use higher bandwidths on demand during the week. Buying out a particular bandwidth also reduces the perminute prices of the remaining (higher) bandwidths.

\section{Demographics of INDEX Subjects}

INDEX subjects range in age from 20 years to 72 years, with a mean age of 35 and a median age of 29. Not surprisingly, due to their university affiliation, INDEX subjects have a higher

\footnotetext{
${ }^{2}$ Data on this experiment are currently available for only 40 of the approximately 70 subjects.

${ }^{3}$ When a subject buys out a particular bandwidth, all bandwidths below that can be used at no charge.
} 


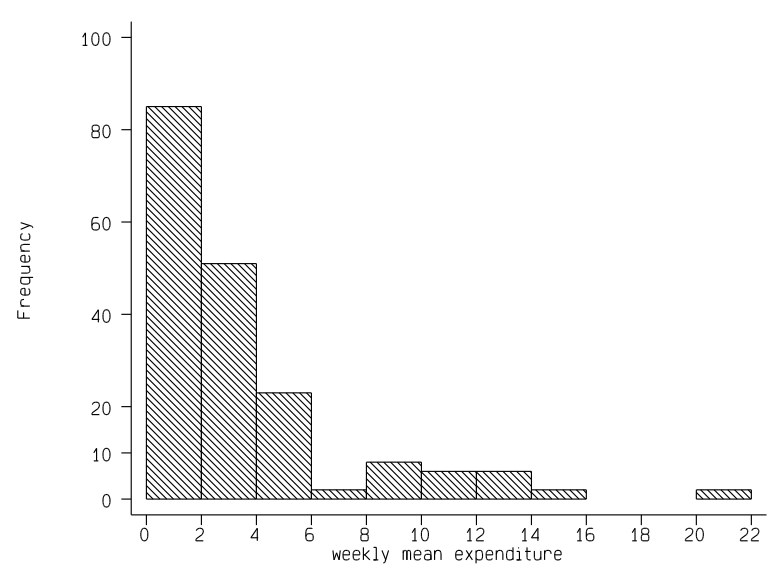

Fig. 2. Expenditure Histogram

level of education compared to the U.S. population. Figure 1 compares the educational achievement of the INDEX subject population with the educational achievement of the U.S. population [U.S. Census Bureau 1999].

While the level of education of the INDEX subjects and of the U.S. population differs significantly, the income distribution of both groups does not appear to differ significantly. Most INDEX subjects are experienced computer and Internet users: 90 percent of INDEX subjects already used the Internet three or more years ago, compared with 9 percent of the respondents in a population-representative Nielsen survey. See [Altmann et al 1999b] for more details.

\section{E. Heterogeneous Preferences of Subjects}

INDEX subjects have heterogeneous preferences. This heterogeneity of preferences is exhibited by large inter-subject variations in weekly expenditures and in weekly transmitted bytes.

An example of the inter-subject variations in weekly mean expenditure is shown in Figure 2. The figure depicts the subjects' mean weekly expenditures for three experiments: Symmetric Bandwidth Minute Pricing, Asymmetric Bandwidth Minute Pricing, and Byte Pricing. The weekly expenditures in these three experiments ranged from a low of $\$ 0.20$ per week to a high of $\$ 21.23$ per week. A more detailed description can be found in [Altmann et al 1999b]. In addition, INDEX subjects spent a low of $\$ 0.61$ per week to a high of $\$ 12.56$ per week in the Flat-Rate Buy-Out experiment, with 27.5 percent of the subjects spending less than $\$ 3$ per week and 20 percent spending more than $\$ 8$ per week.

Looking at the expenditures in different experiments, it becomes obvious that the disparities in expenditures are not simply due to environmental or seasonal effects. They are rather an inherent characteristic of individual demand. Figure 3 shows this effect: The mean weekly expenditure of $48 \%$ of the INDEX subjects in the Symmetric Bandwidth Minute Pricing, Asymmetric Bandwidth Minute Pricing, and Byte Pricing Ex-

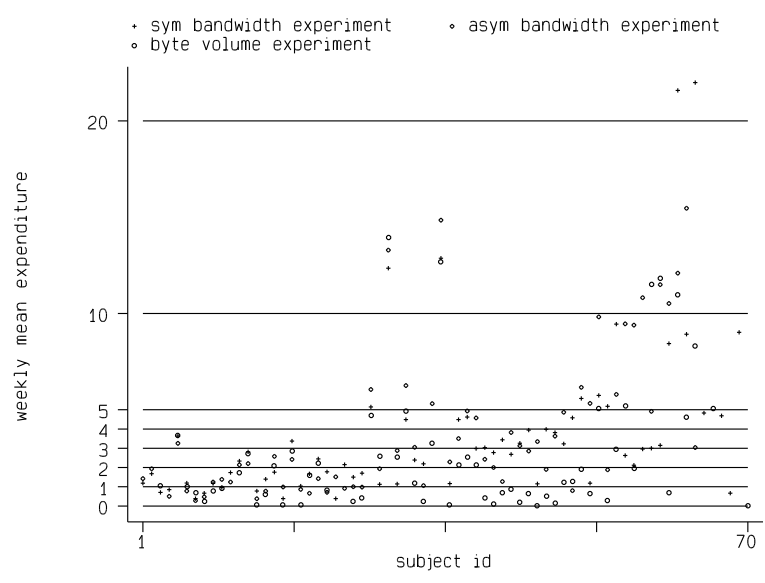

Fig. 3. Budget

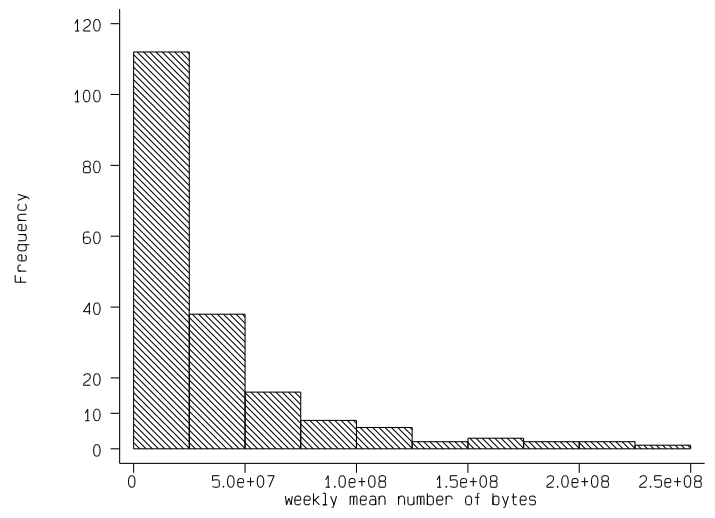

Fig. 4. Bytes Histogram

periments varied only in a range of $\$ 2$. Considering that users were facing widely varying prices over the course of the three disparate experiments, this result gives clear evidence that a significant percentage of users have an exact idea of how much they are willing to spend for Internet service in a given time period. Another $24 \%$ of our subjects also set relatively tight constraints on their Internet budget, allowing for a maximum variation of $\$ 4$. Only the remaining $26 \%$ displayed a significantly wider variation in their expenditure distribution.

Figure 4 shows the inter-subject variation in weekly bytes transmitted for the Symmetric Bandwidth Minute Pricing experiment, the Asymmetric Bandwidth Minute Pricing experiment, and the Byte Pricing experiment. The weekly mean number of bytes transmitted ranges from 0.5 Mbyte to 250 Mbyte. 50 percent of the samples represent light usage of less than 25 Mbyte, while 25 percent of the samples demonstrate heavy usage of more than 50 Mbyte. 


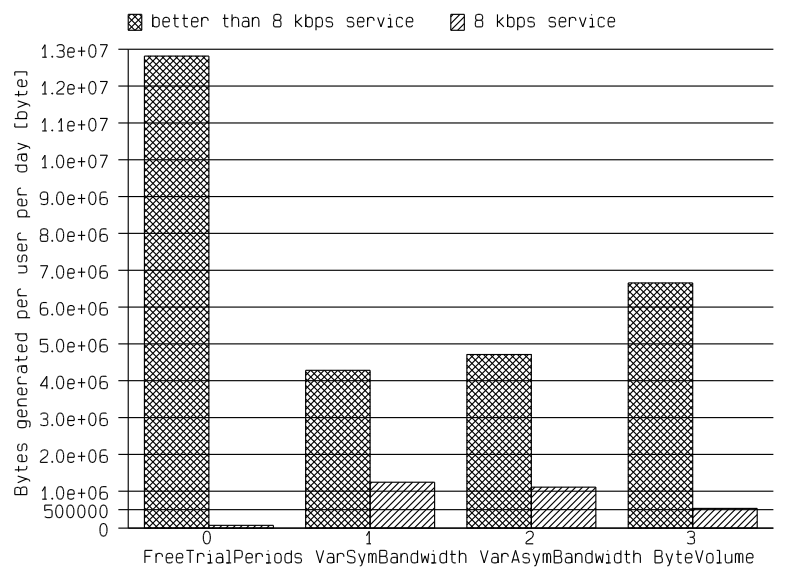

Fig. 5. Average Number of Bytes Transmitted

\section{Over-Usage by Flat-Rate Plans}

INDEX data gives an estimate of the magnitude of increase in usage under flat-rate plans compared with bytes transmitted under usage-based pricing plans. Figure 5 shows the average number of bytes transmitted in the Symmetric Bandwidth Minute Pricing, the Asymmetric Bandwidth Minute Pricing, and the Byte Pricing experiments. During the free trial periods (which is equivalent to flat-rate pricing plans), the number of bytes transmitted are singificantly higher than the bytes transmitted in any of the three usage-based pricing experiments. The bytes transmitted by subjects during the free weeks is twice the nummber of bytes transmitted in the Byte Pricing experiment, and almost three times the byte volume transmitted in the Minute Pricing experiments.

When a bandwidth was bought out in the Flat-Rate Buy-Out Option experiment (i.e. the user had unlimited access at the bought-out bandwidth), the mean number of bytes transmitted per user day was 10.71 Mbyte, compared with a mean of 1.27 Mbyte per user day in the weeks in which no bandwidth was bought out. This is shown in Figure 6.

Interestingly, large usage differences exist even for the same subject in the weeks in which the subject had flat-rate, unlimited access compared with the weeks in which the subject paid purely usage-based charges. For example, 57.9 percent of the INDEX subjects transmitted at least three times as much volume in the weeks in which they had unlimited access compared with their transmitted volume in the weeks in which they paid usage-based charges [Chu 1999].

The INDEX findings are that subjects transmit significantly greater number of bytes under flat-rate unlimited access service plans compared with usage-based service plans.

\section{Attractiveness of Flat-Rate Plans}

The majority of the INDEX subjects selected a flat-rate unlimited-access service plan. 85 percent of the subjects bought out a bandwidth in at least half of their weeks in the Flat-Rate Buy-Out Option experiment. 52.5 percent of the IN-

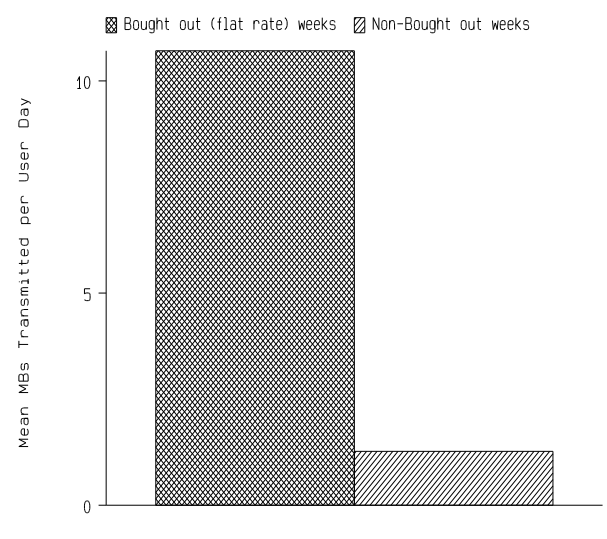

$\overline{\text { staTa'm }}$

Fig. 6. Comparison of Usage Between Bought-Out (Flat-Rate) and Non Bought-Out Weeks

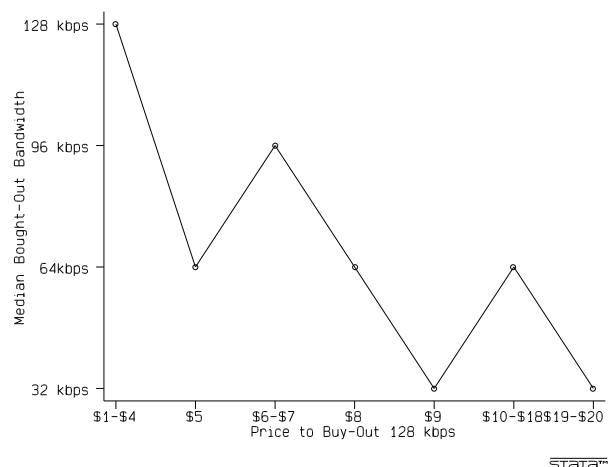

Fig. 7. Median Bought-Out Bandwidths Fall as the Flat-Rate Buy-Out Prices for $128 \mathrm{kbps}$ Rise

DEX subjects bought out a bandwidth in every one of their weeks in the experiment. The mean weekly fixed charge paid by the subjects in the weeks in which a bandwidth was bought out was $\$ 5.25$, which is approximately equal to the monthly flat-rate of $\$ 21$ charged by major ISPs for Internet access.

When the price for buying out the bandwidths rose, the INDEX subjects had two options: they could continue buying out the same bandwidths as they had previously, thereby staying at their previously selected bandwidth but paying a higher flat fee. Alternatively, they could select a lower bandwidth, keeping or reducing the expenditures. Many subjects chose to buy out a lower bandwidth and lower their flat fee as the buy-out prices increased. For example, as shown in Figure 7, when the weekly buy-out price for $128 \mathrm{kbps}$ was between $\$ 1$ and 
$\$ 4$, the median bandwidth that was bought out was $128 \mathrm{kbps}$, which meant that almost everyone who chose the flat-rate option chose to buy out the $128 \mathrm{kbps}$ service. However, when the weekly buy-out price for $128 \mathrm{kbps}$ rose to $\$ 6$, the median bought-out bandwidth dropped to $96 \mathrm{kbps}$, meaning that half of the INDEX subjects who chose the flat-rate option chose to buy out $96 \mathrm{kbps}$ or an even lower bandwidth for which they paid a flat-rate of $\$ 4.50$ (for $96 \mathrm{kbps}$ ) or less (for bandwidths lower than $96 \mathrm{kbps}$ ), and the remaining half who chose the flatrate option chose to buy out $128 \mathrm{kbps}$ for which they paid the full $\$ 6$. Under a weekly buy-out price of $\$ 8$, the median bandwidth that was bought out had dropped to $64 \mathrm{kbps}$ [Chu 1999].

This behavior is consistent with our earlier findings that many subjects appeared to have a narrow range of expenditures across the different experiments (Figure 3). This behavior also suggests that the subjects cared about having a flat-rate option for basic access but most of them did not appear to care as much about which particular bandwidth they were able to use for access under the flat-rate option. It may be because they were always able to access a higher bandwidth on demand at any time in the future.

Additional evidence that the subjects value flat-rate pricing for basic access is the fact that many subjects appeared to be paying a premium to buy out a bandwidth for the week.

The premium is defined as the difference between the subjects' total expenditures for his/her usage that week minus what the subjects' total expenditures would have been under the cost-minimizing choice. To compute each subject's costminimizing choice for a particular week, we took the subject's chosen vector of connect times that week at each bandwidth. Then, we computed the cost of that vector at every possible buy-out choice. This method of computing the minimum charge for a particular choice tends to overstate the number of cost minimizing choices since a subject is likely to use more connect time when the marginal price is zero than when the price is positive.

Using a conservative estimate of the cost-minimizing choice, we find that in 23 percent of the weeks in which a bandwidth was bought out, the subject's bandwidth buy-out decision was not cost-minimizing. The premium as a percentage of the mean total weekly expenditures ranged from a low of 0.18 to a high of 100 percent, with a median of 50 percent. In monetary terms, the premiums ranged from a low of $\$ 0.65$ to a high of $\$ 9.21$, with a median of $\$ 2.02$. Figure 8 shows, for the 23 subjects with non cost-minimizing choices, the subjectspecific mean premium for the weeks that were bought out and were not cost-minimizing.

\section{Demand For FleXibility}

In all experiments, INDEX subjects made use of a wide range of bandwidths, showing that their demand for network service was variable over time. Almost every subject purchased high quality service at least sometimes.

Figure 9 shows a histogram displaying the number of dif-

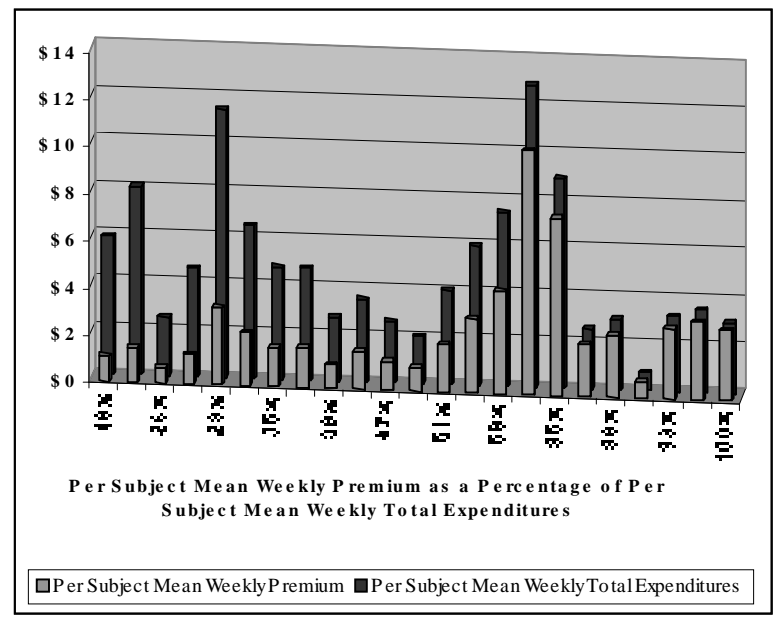

Fig. 8. Individual-Specific Values of Mean Weekly Premiums compared with Individual-Specific Values of Mean Weekly Total Expenditures

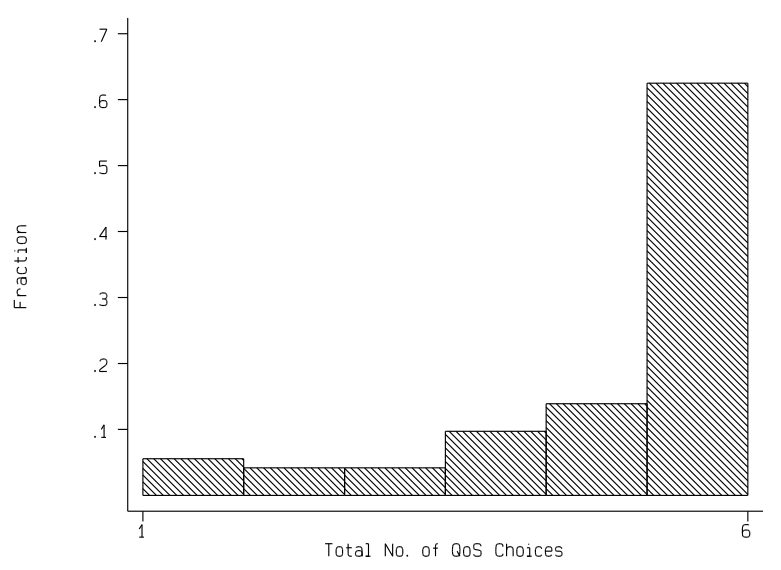

Fig. 9. QoS Choices - Histogram

ferent QoS choices that subjects made over the entire duration of the Symmetric Bandwidth Pricing experiment. $62.5 \%$ of the subject population made use of the entire range of options (8kbps to $128 \mathrm{kbps}$ ). $75 \%$ used at least five different bandwidths.

In the Flat-Rate Buy-Out Option Pricing experiment, 82.5 percent of INDEX subjects, who had paid a flat-fee to attain unlimited access at a particular bandwidth for the week, continued to use higher, non-bought-out bandwidths on occasion even though they were charged per-minute prices for using the non bought-out bandwidths. Another 10 percent of the subjects bought-out the $128 \mathrm{kbps}$ service in every week and had unlimited access to the highest available bandwidth. Hence only 7.5 percent of the subjects did not use higher, non-bought-out bandwidths on demand.

These results provide support for the contention that subjects want the ability to use higher, non-bought-out bandwidths on occasions when they have the need to do so. 


\section{CONCLUSION - \\ A Flexible Service Plan is NeEded}

The results we presented in this paper showed that there is demand for a more flexible service plan than the currently predominant flat-rate service plan.

From the user's perspective, two issues are important: firstly, flexibility in choosing QoS for Internet access and, secondly, convenience of not being bothered with a constantly ticking meter.

The results we presented showed that INDEX subjects appreciate the flexibility of requesting higher QoS on demand, even if they had to pay a per-minute rate for the service. $75 \%$ of the subjects used the entire range of options given to them. However, the convenience of not thinking about ticking meters is very important to the user. As the analysis showed, subjects are willing to pay a premium for not getting charged by a perminute service plan.

Considering these results, we can conclude that a combination of both features within a service plan might result in a very successful service plan.

The service plan that we are proposing combines these userappreciated features. Under the proposed service plan, the user chooses a flat-rate basic service which provides access to the Internet at a certain basic rate. This is a rough segmentation by tiering services. In addition to this, the ISPs offers all customers the ability to request higher bandwidth on demand. This service will be charged based on usage, which might be per-byte, per-minute, or a combination of the two.

From the ISP's perspective, this kind of service plan is also very attractive, since it deals with the issue of over-usage under a flat-rate service (which would be very critical for broadband access). Deploying such a service plan, the ISP can attractively offer broadband access to the group of heavy Internet users without limiting the Internet access service to certain kind of applications. For example, @ Home restricted the use of streaming media to their customers.

In addition to that, this kind of service plan enables the ISPs to get additional revenues beside the revenues they would get from purely flat-rated services. ISPs could meet the current demand of users at any time. If users who chose a basic service require better quality service now and then, the ISP can provide them with such a service and charge them based on their usage under this proposed service plan. The ISP gets the surplus the user is willing to pay in these situations. This statement is also supported by our data. INDEX received revenues of only 7.75 cents per Mbyte in the bought-out weeks compared with revenues of 30.41 cents per Mbyte in the non-bought-out weeks.

Since this service plan model meets the needs of users and ISPs, it might be the preferred service plan in a more competetive ISP market.

The overall conclusion we can draw is that users prefer a pricing structure in which they pay a flat-rate for basic service and have access to higher bandwidths that they can utilize on demand.

\section{REFERENCES}

[1] J. Altmann, B. Rupp, and P. Varaiya, 1999a, “The Case for Quality of Service on Demand," ISQE'99, Workshop on Internet Service Quality Economics, in press, Cambridge, MA, USA, December 1999.

[2] J. Altmann, B. Rupp, and P. Varaiya, 1999b, "Internet Demand under Different Pricing Schemes," EC'99, ACM Conference on Electronic Commerce (SIGecomm), Denver, Colorado, USA, November 1999.

[3] K. Chu, 1999, "User Reactions to Flat-Rate Options under Time Charges with Differentiated Quality of Access: Preliminary Results from INDEX,' ISQE'99, Workshop on Internet Service Quality Economics, in press, Cambridge, MA, USA, December 1999.

[4] A. Hoag, 1997, "Speed and the Internet: The Effects of High Speed Access on Household Usage," Proceedings of the 25th Telecommunications Policy Research Conference, section IX, pp. 24-37, 1997.

[5] S. Shenker, D. Clark, D. Estrin, Shai Herzog 1996, "Pricing in Computer Networks: Reshaping the Research Agenda," Telecommunications Policy, vol. 20(3), pp. 183202, 1996.

[6] U.S. Census Bureau 1999, Educational Attainment Table 1, March 1998 (table posted on the web at www.census.gov), 1999. 